\title{
Extensão popular em educação ambiental e a formação de educadores/as ambientais
}

\author{
Popular extension in environmental education and the training of environmental educators \\ Extensión popular en educación ambiental y formación de educadores/as ambientales
}

TIAgo ZanQuêta de SOUZA ${ }^{1}$

UNIVERSIDADE DE UBERABA, UNIUBE, UBERABA-MG, BRASIL

\begin{abstract}
RESUMO
Este artigo tem por objetivo apresentar, a partir de nossas compreensões em torno da convivência em diálogo, na comunidade de trabalho, o quem somos e a construção colaborativa no fazer dessa prática social, com a finalidade de compreender melhor nossos traços identitários e os processos educativos que emergem desse contexto. Além disso, tem a finalidade de discutir como, considerando-se os processos educativos, pode-se pensar na extensão enquanto tripé de sustentação da universidade. Ao fazer extensão popular, nutrimos uma perspectiva teórica e epistemológica para a extensão universitária que seja capaz de sugerir caminhos possíveis para outras realizações entre a universidade e a sociedade, e entre a sociedade e a universidade, ou seja, em ambos os sentidos, na busca pelo enfrentamento da desumanização em curso.
\end{abstract}

Palavras-chave: Processos Educativos. Extensão Popular. Educação Ambiental.

\begin{abstract}
This article aims to present, based on our understanding of living in dialogue, in the work community, who we are and the collaborative construction in making this social practice, with the specialization of better our identity traits and the educational processes that emerge from this context. In addition, it has to discuss how, through educational processes, one can think of extension as a tripod supporting the university. When doing popular extension, we nurture a theoretical and epistemological perspective for university extension that is capable of suggesting possible paths for other achievements between a university and a society, and between a society and a university, that is, in both senses, in the search for the confrontation of the dehumanization in progress.
\end{abstract}

Keywords: Educational Processes. Popular Extension. Environmental Education.

\section{RESUMEN}

Este artículo tiene como objetivo presentar, a partir de nuestra comprensión del vivir en diálogo, en la comunidad de trabajo, quiénes somos y la construcción colaborativa en la realización de esta práctica social, con el fin de comprender mejor nuestros rasgos identitarios y procesos educativos que emergen de este contexto. Además, tiene como objetivo discutir cómo, a través de procesos educativos, se puede pensar en la extensión como un trípode de apoyo para la universidad. Al hacer extensión popular, alimentamos una perspectiva teórica y epistemológica para la extensión universitaria que sea capaz de sugerir posibles caminos para otros logros entre la universidad y la sociedad, y entre la sociedad y la universidad, es decir, en ambos sentidos, en la búsqueda de confrontación de la deshumanización en curso.

Palabras clave: Procesos Educativos. Extensión Popular. Educación Ambiental.

\footnotetext{
${ }^{1}$ Professor da Uniube. E-mail: tiago.zanqueta@ uniube.br. ORCID: https://orcid.org/0000-0002-2690-4177.
} 


\section{INTRODUÇÃO}

O presente artigo foi elaborado com base em reflexões tecidas ao longo da pesquisa de doutorado em educação, realizada entre 2014 e 2017, junto a um grupo de estudantes de Engenharia Ambiental da Universidade de Uberaba, na cidade de Uberaba/MG, que fazem extensão popular com um grupo de moradoras/es do Bairro Vila Esperança II e Jardim Anatê, da mesma cidade, constituindo, a partir dessa prática, uma comunidade de trabalho.

O referencial teórico da pesquisa está atrelado ao da Educação Popular, da Extensão Popular e da Educação Ambiental, especificamente da Educação Ambiental Crítica. Traz como objetivo geral conhecer os processos educativos que propiciam a formação de engenheiras/os ambientais como educadoras/es ambientais, a partir da prática social anteriormente citada.

A metodologia da pesquisa é de abordagem qualitativa, conforme Bogdan e Biklen (1994), com finalidade descritivo-exploratória, como propõe Vergara (2009), valendo-se da pesquisa de campo, com a coleta de dados pela observação direta, como recomenda Marconi e Lakatos (2002), com registros realizados em diários de campo. Ao todo, foram realizados 17 encontros realizados juntos à comunidade de trabalho. Todos os encontros foram gravados e posteriormente transcritos e discutidos pelos membros da referida comunidade. Análise de Conteúdo, conforme preconiza Bardin (2006), é a metodologia de análise dos dados.

Nesse artigo, a partir de nossas compreensões em torno da convivência em diálogo, na comunidade de trabalho, apresentamos uma das categorias de análise que emergiram dos dados produzidos na pesquisa, que é "o quem somos e a construção colaborativa no fazer dessa prática social [extensão popular em educação ambiental]", com a finalidade de compreender melhor nossos traços identitários e os processos educativos que emergem desse contexto. Em seguida, direcionamos nossos olhares para a compreensão dos processos educativos inerentes ao fazer da educação ambiental, retomando os conceitos de meio ambiente e sua relação com a educação ambiental e a extensão realizada pela e na comunidade de trabalho, com a finalidade de discutir como, considerando-se os processos educativos, pode-se pensar na extensão enquanto tripé de sustentação da universidade e como se dá a formação de educadores/as ambientais.

\section{A COMUNIDADE DE TRABALHO: O QUEM SOMOS E A CONSTRUÇÃO COLABORATIVA DO FAZER EXTENSÃO POPULAR}

Partimos do princípio de que a convivência, nesse caso, metodológica, é fundamental para que a comunidade de trabalho, assim como a compreendemos, nesse contexto, consiga promover o diagnóstico das necessidades - sejam elas de ordem social, política, econômica e ambiental. De acordo com Silva e Araújo-Olivera (2004, n.p.),

\footnotetext{
Uma comunidade de trabalho, tal como a entendemos, se constitui em torno de objetivos comuns que ultrapassam a ordem do pessoal, se situam e enraízam em compromisso com a construção de uma sociedade justa que garanta iguais direitos e tratamento diverso para diferentes condições, circunstâncias, oportunidades sóciohistórico-sociais.
}

A comunidade de trabalho foi constituída pelas/os estudantes do curso de Engenharia Ambiental da Universidade de Uberaba, em Extensão Popular, pelo pesquisador e por um grupo de moradoras/es do bairro Vila Esperança II e do Jardim Anatê, que frequentam a casa espírita João Urzedo, da cidade de Uberaba/MG. 
É a partir do uso da sensibilidade, da exploração das sensações, do diálogo entre os diversos saberes, do popular e científico, especialmente, como sustenta a Extensão Popular, numa constante interação, que se deu a pesquisa. Ou seja, a convivência torna possível, conforme coloca Brandão (2005, p.86), aprendermos

[...] bem mais do que os simples adestramentos dos animais com quem compartimos o planeta Terra. Aprendemos não apenas os saberes do mundo natural, mas a complexa teia de símbolos, de sentidos e de significados que constituem o mundo da cultura. Quase tudo o que nós vivemos em nossas relações com outras pessoas ou mesmo com o nosso mundo, como no próprio contato direto com a natureza, pode ser, também, um momento de aprendizado. Podemos estar ou não conscientes disto, mas cada troca de palavras, cada troca de gestos, cada reciprocidade de saberes e de serviços com uma outra pessoa, costuma ser também um momento de aprendizagem. De uma para a outra, as pessoas que se encontram, conversam, dialogam, deixam passar de si mesmos à outra algo de suas palavras, de suas idéias, de seus saberes, de suas sensibilidades. Querendo ou não (mas é melhor estar querendo) estamos, no conviver com outros e com o mundo, nos ensinando e aprendendo.

É importante destacar, conforme coloca Valla (1996), que a formação de cada uma/um, a sua história de vida e as suas vivências cotidianas, condiciona uma determinada leitura do outro, o que não implica, necessariamente, a compreensão de tudo o que a/o outra/o fala, mas do que, na verdade, desperta maior atenção, pelo que mais é notório para a/o pesquisadora/or.

Valla (1996) ressalta o necessário cuidado com a interpretação da fala do outro, com o objetivo de evitar julgamentos apressados, uma vez que o que se apresenta como "[...] falta de iniciativa e/ou apatia é, para a população, uma avaliação (conjuntural e material) rigorosa dos limites de sua melhoria" (p. 181). Caso contrário, uma interpretação pode levar a "[...] uma suposta identidade, consciência de classe e organização, que, na realidade, é uma fantasia nossa" (MARTINS, 1989, citado por VALLA, 1996, p. 182).

A construção do conhecimento e da aprendizagem se dá a partir do que é experienciado, do que é vivido. Segundo Larrosa-Bondía (2002, p. 28),

[...] a experiência já não é o que nos acontece e o modo como lhe atribuímos ou não um sentido, mas o modo como o mundo nos mostra sua cara legível, a série de regularidades a partir das quais podemos conhecer a verdade do que são as coisas e dominá-las.

Teixeira e colaboradoras/es (2015), citando Jares (2008), colocam que a convivência pressupõe a construção de valores, de sistematização de experiências, de modos de organização, de maneiras de pensar, relacionar e agir, de metodologias para enfrentar conflitos, de compreensões linguísticas, de modos de expressar os sentimentos, expectativas sociais e educativas, de cuidado, etc. Na convivência, busca-se a eliminação de divergências que podem se manifestar nas desqualificações e negações de outras culturas. O diálogo permite buscar a compreensão de outras culturas e o estabelecimento de acordos para que seja possível a construção da unidade na diversidade ${ }^{2}$, assim como coloca Freire (2008).

Para Dussel (1977) a aproximação de uma pessoa a outra é fraterna, o que indica que a proximidade é estar numa relação fraterna, encurtando distâncias para alguém que pode

\footnotetext{
${ }^{2}$ Paulo Freire (2008) observa que existe uma busca por unidade na diferença, como um processo, uma luta que introduz a criação da multiculturalidade, que ele entende como um fenômeno que implica convivência num mesmo espaço de diferentes culturas. Segundo Freire (2008), a multiculturalidade é também uma criação histórica que implica decisão, vontade política de mobilização, organização de cada grupo cultural com vistas a fins comuns, o que vai demandar uma certa prática educativa coerente com essa postura. Isso significa também que existe uma demanda por uma nova ética fundada no respeito às diferenças.
} 
esperar-nos ou rejeitar-nos, dar-nos a mão ou ferir-nos. Esse ato é, para o autor, a celebração da vitória decorrente da luta comum, que é o gozo da celebração pela liberdade adquirida. É a partir dessa compreensão que entendemos a aproximação entre o grupo de estudantes e os populares frequentadores da casa espírita, que juntos constituíram a comunidade de trabalho. A aproximação é o primeiro passo para a convivência, que para nós tem o sentido de viver com, algo mais do que estar perto ou junto, é estabelecer uma sintonia de sentimentos que nos permite agir em prol do bem comum, ou seja, da vocação ontológica para o ser-mais, como coloca Paulo Freire (2008), mesmo sabendo que, conforme coloca Silva (1987), exista conflitos. Dessa forma, a convivência é entendida como possibilidade, e não como certeza, uma vez que é parte do processo de humanização. A convivência, dessa forma, é que orienta o quem somos "nós".

A convivência pressupõe diálogo, que traz dois sentidos: o primeiro põe a convivência entre o grupo extensionista e os populares que juntos estruturam a comunidade de trabalho. $\mathrm{O}$ diálogo como método, na perspectiva de Freire (2008), permitiu ao grupo extensionista dizer a sua palavra, da mesma forma como os populares disseram a sua. Os anseios do grupo para o "como seria" desenvolver a extensão, alcança o segundo sentido, que aponta o estabelecimento do diálogo como elemento que favorece a convivência, na medida em que possibilita a problematização e a busca por soluções de problemas fundamentais para o bemestar de toda a população dos bairros que circundam a casa espírita. A partir do momento em que os grupos que compõem a comunidade de trabalho passaram a se conhecer melhor, surgiram laços de amizade, de fraternidade, de amorosidade e de confiança, elementos que ficaram fortalecidos somente pela convivência em diálogo.

A comunidade de trabalho entende que os saberes que a circundam têm raízes populares, na perspectiva dos populares e também dos estudantes, do mesmo modo que tem raízes científicas, em ambas as perspectivas. Destacamos, por isso, que existe a busca pela igualdade entre os saberes, com a finalidade de não os hierarquizar, pois como afirmava Freire (2005, p.68), “[...] não há saber mais, nem saber menos, há saberes diferentes”, que se complementam. Entendemos também que esses saberes estão vinculados ao saber de experiência feito, na perspectiva de Larrosa-Bondía (2002), uma vez que para o autor, a experiência não é o que acontece, mas o que nos acontece, o que nos passa, o que exige parar para pensar, parar para olhar, parar para escutar, pensar mais devagar, olhar mais devagar e escutar mais devagar. Dessa forma, as experiências vividas são particulares, subjetivas, relativas ao contexto vivido, pessoal, o que, segundo Valla (1996), carece de cuidado no momento da interpretação. Destacamos ainda que esses saberes emergem do convívio dialógico, que encaminha para a construção de um outro saber, coletivo, colaborativo, que supera a consciência ingênua e atinge a consciência crítica sobre a realidade (FREIRE, 2005), a fim de superar a opressão em busca da libertação, não como utopia, mas como possibilidade concreta.

A comunidade de trabalho é um espaço de trabalho, pesquisa, exposição de práticas, dinâmicas e vivências que possibilitaram a construção coletiva do conhecimento. Nela e por meio dela não se ensinou, aprendeu-se em "reciprocidade de consciências", conforme Fiori, citado por Freire (2005, p.06). Existiram momentos em que diversas pessoas assumiram o protagonismo da liderança, a fim de propiciar condições favoráveis ao trabalho do grupo. A comunidade de trabalho pautou-se também na tentativa do exercício do "poder obediencial ${ }^{3 / ،}$,

\footnotetext{
${ }^{3}$ Poder obediencial é, segundo Dussel (2007) e conforme também aponta Souza (2017) o exercício delegado do poder de todo representante que, atribuído de certa autoridade, cumpre satisfatoriamente em nome de toda a comunidade, os encargos de seu ofício; atua como delegado, eleito pela maioria, trabalhando sempre em favor do povo, escutando suas exigências e reclamações, de modo a cumprir a pretensão política de justiça; de outra maneira, é do político honesto, reto, que pode aspirar ao exercício do poder por ter a posição subjetiva necessária para lutar em favor da felicidade empiricamente possível de um povo.
} 
conforme coloca Dussel (2007), uma vez que o articular concreto do poder, produz o exercício da delegação, que no caso da comunidade de trabalho, pode abrir caminho para o fortalecimento da "potentia", ou seja, lutando para que as necessidades da comunidade de trabalho, essencialmente dos populares que a compõem, fossem atendidas. Dessa forma, entendemos que o grupo extensionista esforçou-se para que, nos momentos em que atuou na orientação ou condução de alguma atividade ou ação, o poder naquele momento delegado não se pusesse acima da comunidade, mas a serviço dela. Desse modo, novamente, existia a intenção pela construção coletiva.

\section{EDUCAÇÃo AMBIENTAL EM DIÁLOGO NO FAZER DA EXTENSÃO POPULAR: A FORMAÇÃo DE EDUCADORAS/ES AMBIENTAIS}

Loureiro (2014), afirma, citando o Conselho Nacional de Educação, que, na introdução das Diretrizes Curriculares Nacionais da Educação Ambiental (DCN), o adjetivo "ambiental" atrelado à educação, no contexto da América Latina não é empregado para especificar um tipo de educação. Trata-se de um elemento estruturante que demarca um campo político de valores e práticas, capaz de mobilizar pessoas comprometidas com a prática político-pedagógica transformadora e emancipatória. Entendemos que a educação ambiental crítica e a corrente da educação ambiental popular assumida pelo grupo extensionista junto à comunidade de trabalho pode produzir conhecimento na práxis. O fazer educação ambiental, nesse caso, pressupõe o diálogo, a convivência, a construção de uma consciência crítica a partir de uma realidade concreta (FREIRE, 2008).

O encontro da educação ambiental com o pensamento crítico dentro do campo educativo parece-nos ser um encontro que, como afirma Dussel (2007) potencializa a vontade-de-vida, pois a educação crítica tem suas raízes nos ideais democráticos e emancipatórios do pensamento crítico aplicado à educação. A Educação Popular rompe com a visão de educação tecnicista, difusora e repassadora de conhecimentos, e propõe à educação, assumir a mediação na construção social de conhecimentos a partir da práxis.

Paulo Freire (2005), ensina-nos a pensar a educação como formação de pessoas emancipadas, isto é, autoras/es de sua própria história. Dessa forma, podemos chegar à compreensão do como é que o grupo extensionista entende a educação ambiental que faz e como é que a comunidade de trabalho a compreende, na perspectiva dos populares. O diálogo foi fundamental para a compreensão da educação ambiental que foi e é realizada. Embora o grupo extensionista assuma a educação ambiental popular como corrente orientadora, nem sempre as práticas cotidianas estiveram voltadas ou atreladas a essa concepção, pois entendemos que a construção da consciência crítica se dá mediante uma análise profunda da realidade vivente, portanto, que está em um constante processo de reconhecimento. Entendemos também que a comunidade de trabalho atua a partir de uma perspectiva educativa, que conforme Sauvé (2005) é centrada também no grupo social, uma vez que reconhece que o ser humano desenvolveu uma relação de alienação a respeito do entorno de onde vive, recomendando, como possibilidade de superação desse estado, uma educação que pressupomos tratar-se da educação popular, a fim de desenvolver a autonomia, a paciência, o silêncio, o senso crítico e promover a construção de valores éticos.

De acordo com Freire (2005) a natureza humana se constitui ao longo da história e historicamente o ser humano se transforma no que é, embora seja um ser finito, inconcluso, inserido em um permanente movimento de busca por ser mais. Para Freire (2005) embora o ser humano seja vocacionado para ser mais, pode em determinado contexto histórico, perder seu endereço e distorcer sua vocação, desumanizando-se. A desumanização não é vocação para o ser mais. A vocação para o ser mais demanda liberdade, possibilidade de decisão, de 
escolha, de autonomia, a fim de que se movam no tempo e no espaço, no cumprimento de sua vocação, realizando seu destino, mas se refazendo sempre em diferentes âmbitos, como no social, político, econômico, e incluímos aqui o ambiental. Nesse sentido, entendemos como as/o estudantes/e de Engenharia Ambiental se enxergam, se compreendem e se reconhecem como engenheiras/o ambientais/l (ainda que em curso), e como a comunidade de trabalho também os compreendem, enxergam e reconhecem a partir da perspectiva dos populares.

Entendemos que o conceito de meio ambiente que pode orientar a educação ambiental realizada na comunidade de trabalho é aquele que o reconhece como um lugar de cooperação e de parceria para realizar as mudanças desejadas no seio da coletividade, conforme propõe Sauvé (2005). Nesse contexto, a convivência vai permitir o aprendizado de como viver e trabalhar em conjunto, pois, é preciso que se aprenda a discutir, a escutar, a argumentar, a convencer, a comunicar-se eficaz e dialogicamente entre pessoas que trazem saberes de diversos tipos, como os acadêmicos, os de experiência de vida. Desse modo, a ação está associada a um processo constante de reflexão crítica.

Partimos da compreensão de Cruz (2017) quando afirma que fazer extensão popular é propor a mudança social e das relações educativas presentes na sociedade, ou seja, é lutar contra todo tipo de verticalismo, autoritarismo, hierarquia, irracionalidade, exploração e desumanização em curso. Populares, estudantes e pesquisador, a partir do momento que se constituíram como comunidade de trabalho, configuraram um ato-limite em busca de um inédito viável, ou seja, a comunidade de trabalho pode ter sido a mola propulsora para a mudança, para a busca de soluções dos problemas ambientais enfrentados, para a superação das situações-limites (FREIRE, 2005) que limitam a vontade-de-vida (DUSSEL, 2007). Nesse contexto, entendemos a necessidade de olhar qual foi a contribuição das/o estudantes/e para com os populares na comunidade de trabalho (sem deixar de olhar a contribuição destes populares para com os estudantes) durante a convivência em diálogo ao fazer extensão popular.

Segundo Freire (2005), podemos ter diferentes atitudes diante situações-limites: ou as percebemos como um obstáculo que não conseguimos transpor, ou como algo que não queremos transpor, ou ainda como algo que sabemos que existe e que precisa ser rompido e então nos empenhamos na sua superação. Nesse caso, a situação-limite foi percebida criticamente e por isso aquelas e aqueles que a entenderam querem agir, desafiados que estão e se sentem com potencial para resolver da melhor maneira possível, num clima de esperança e de confiança, os problemas que vivem. No caso da comunidade de trabalho, ficou evidente o problema ambiental enfrentado com a ausência de uma passarela ${ }^{4}$ que liga os bairros Vila Esperança II e Jardim Anatê. Quando a comunidade de trabalho foi constituída, essa situaçãolimite já estava posta, ou seja, os populares já a entendiam na sua profundidade, na sua essência, destacando do que está aí e que pôde ser visto como um problema.

Como algo "percebido" e "destacado" da vida cotidiana o "percebido-destacado" (FREIRE, 2005) que não permaneceu como tal, passando a ser um tema-problema a ser enfrentado, discutido e superado, o que ainda não aconteceu, mas está no caminho. Às ações desenvolvidas para romper as situações-limites, Freire (2005) chama de atos-limites, que abrem caminhos para a superação do problema, implicando uma postura decidida frente ao mundo, pautada na ação com reflexão, buscando o ser-mais, surgindo, a partir disso, o inédito-viável, que é, pois, em última instância, algo que o sonho utópico sabe que existe, mas que só será conseguido pela práxis libertadora que pode passar pela teoria da ação dialógica. Nesse momento, a comunidade de trabalho vive esse inédito viável. O que-fazer evidencia a

\footnotetext{
${ }^{4}$ Essa passarela ligaria o bairro Vila Esperança II, onde se localiza a casa espírita João Urzedo, ao bairro Jardim Anatê. A comunidade de trabalho compreende que a ausência da passarela naquela localidade é um problema ambiental, que mais que limita o direito de ir e vir, limita a vida a partir do risco de morte ao tentar atravessar a rodovia MG-262, de intenso tráfego automotor em alta velocidade.
} 
preocupação da comunidade de trabalho com a transformação da realidade, tomando a extensão popular que, enquanto prática social experenciada na comunidade de trabalho, buscou o reconhecimento das necessidades dos populares pela sociedade; tem tentado ainda corrigir distorções e injustiças socioambientais, além de pensar, refletir, discutir e executar ações que visem a superação das situações-limites percebidas.

De acordo com Oliveira e colaboradores (2009), os processos educativos se desenrolam em práticas sociais, e as pessoas que participam de tais práticas interconectam o aprendido em uma prática com o que estão aprendendo em outra, ou seja, o aprendido em casa, na rua, na quadra comunitária do bairro, em todos os espaços por onde passa, como ponto de apoio e referência para novas aprendizagens. Vale ressaltar que as experiências e contextos presentes nos espaços universitários nem sempre são identificados pela instituição; e, no caso de sê-lo, não são reconhecidos como academicamente qualificados.

Quanto à capacidade de uma educação promover valores socioambientais, é importante destacar que o processo educativo não se dá apenas pela aquisição de informações, mas sobretudo pela aprendizagem ativa, entendida como construção de novos sentidos e nexos para a vida. Trata-se de um processo que envolve transformações no sujeito que aprende e incide sobre sua identidade e posturas diante do mundo. A educação ambiental popular age dentro de um universo onde a educação é uma prática de formação de sujeitos e produção de valor e, dessa forma se torna uma das mediações educativas afinadas ao espírito da comunidade de trabalho, comprometida com a superação da situação-limite, a partir do trabalho colaborativo fruto da extensão popular.

Nesta perspectiva, a/o educadora/or ambiental é uma mediadora/or da compreensão das relações que os grupos ou comunidade(s) em que se insere estabelecem com o meio ambiente. Atua como um intérprete dessas relações, como facilitadoras/es das ações grupais ou individuais que proporcionam outras experiências e aprendizagens. No caso da comunidade de trabalho, a educação ambiental popular parece ser uma das mediações educativas afinadas ao espírito de uma extensão popular tomada como um processo de caráter educativo e transformador, baseado em uma metodologia participante que permite $o$ desenvolvimento de uma prática social mediante a qual as pessoas envolvidas no processo buscam a construção e sistematização de conhecimentos que as levem a incidir conscientemente sobre a realidade.

\footnotetext{
Dona Maria falou assim: uai, mas do jeito que tá eu to entendendo que eu também sou educadora, e não tenho diploma não, nem estudei direito, só assino meu nome, e eu só sei ensinar meus filhos, esses sim é trazido junto comigo. Moral eu dou para eles, ensino respeitar, que tem que trabalhar direito, que tem que ter amor nas coisas e nunca faltar com respeito a ninguém. Foi quando eu completei: então, na verdade a tentativa é de a gente entender como a gente aprendeu ao longo do tempo de convivência juntos, e pode ter certeza que todas e todos podemos ensinar e aprender com alguém sobre algo ou alguma coisa, algum lugar. Todas e todos somos sim educadoras e educadores ambientais, da vida. Foi quando novamente dona Cidinha disse: se a gente já sabe que ninguém sabe mais que ninguém aqui, que cada um de nós sabe alguma coisa, então é isso mesmo (e deu uma risada bem gostosa). (Recorte do Diário de Campo XVI).
}

Nesse sentido, não apenas as/os estudantes se constroem como educadoras/es ambientais, a partir da extensão popular, mas todas as pessoas envolvidas e comprometidas com a transformação daquela realidade.

A comunidade de trabalho pode ser compreendida, também, como uma interseção entre a "extensão popular", a "convivência" e a "educação ambiental popular". Como já colocado anteriormente, foi constituída a partir da comunhão entre as/os populares frequentadores/as da casa espírita João Urzedo e as/o estudantes universitárias/o, a partir da 
prática social da extensão popular, aqui exercida com a intenção desenvolver a práxis em torno da educação ambiental popular.

A partir do momento que compreendemos o diálogo como elemento estruturante da prática social da extensão popular em educação ambiental popular, realizada na e com a comunidade de trabalho, é possível compreender que, por exemplo, não cabe apenas ao campo da educação ambiental popular, enquanto orientação teórico-prática do grupo extensionista, o desenvolvimento da consciência crítica. Seria ingenuidade de nossa parte acreditar que por meio da extensão popular essa consciência não seria alcançada, se é também um dos objetivos dessa modalidade de extensão. E essa consciência crítica só é atingida porque é forjada na convivência, a partir de um diálogo comunicativo, que alimenta a esperança e encaminha para a superação daquilo que entendemos como situações-limites.

A prática social da extensão popular é um caminho que potencializou, tomando-se o arcabouço teórico motivador da educação ambiental popular, a efetivação de uma comunidade de trabalho que se sustentou e tem se sustentado na convivência, configurando um processo dialógico que encaminha para o exercício da alteridade, da autonomia, do enfrentamento do medo, da tentativa de exercitar o poder obediencial, do estabelecimento da confiança que, mesmo lentamente, é estruturada no respeito e na amorosidade. O quem somos é forjado a partir dessa comunidade de trabalho e os processos educativos inerentes à prática social observada, que se dá na e com a comunidade de trabalho, são inerentes ao que-fazer em torno da situação-limite ou das situações-limites que se apresentaram. Aprender a confiar, a ousar, a comunicar, a dialogar, a enfrentar, a empoderar, a superar a ingenuidade da consciência é permeado por processos que educam as pessoas envolvidas, de modo a encaminhá-las no sentido da construção de um conhecimento conversitário ${ }^{5}$ (FLEURI, 2005), que potencializa projetos emancipatórios, sustentando a função social da universidade e promovendo, possivelmente, a ressignificação dos currículos acadêmicos, a partir de uma análise crítica da realidade que está sendo, com as pessoas e não para elas.

\section{Processos educativos inerentes À eXtensão POPUlar Realizada: algumas CONSIDERAÇÕES}

Embora não tenhamos feito nenhuma análise em torno do ensino, da pesquisa e da extensão de modo articulado, entendemos a necessidade de estabelecer algumas considerações a partir das contribuições da pesquisa que dá origem a esse artigo, a fim de compreender como os processos educativos também podem permitir o re-pensar do papel da universidade.

Ao iniciar suas atividades e vivências neste campo, as estudantes e o estudante se mostraram encantadas/o com a riqueza do conhecimento popular, com as ações populares e comunitárias e com a realização a partir da conquista de avanços em busca de uma educação humanizadora. Disso resultou o refinamento do gosto pela ação em si, de programar atividades, proporcionar o encontro entre as pessoas e incentivar a mobilização da comunidade de trabalho. Com essas ações, o grupo extensionista pode sentir, especialmente, um resultado compensatório como consequência de seu trabalho, inspirado nas ideias transformadoras, nas construções colaborativas, nas mudanças de atitude. Por isso, correram o

\footnotetext{
${ }^{5}$ O conhecimento conversitário, conforme propõe Fleuri (2005) e Souza (2017), se constitui mediante o reconhecimento mútuo entre as diferentes pessoas, dado seu contexto socio-histórico-cultural, que se colocam em relação intensa e crítica a partir do enfrentamento dos desafios emergentes do lugar em que estão enraizadas. É no enfrentamento das situações-limites, de lugares constituídos dinamicamente entre um ser e outro, entre uma cultura e outra, entre uma instituição e outra, que pode ser possível o aparecimento de outras possibilidades de significação e, como consequência, do aperfeiçoamento crítico de cada uma das pessoas que estão nessa relação. O conhecimento conversitário potencializa projetos emancipatórios, sustentando a função social da universidade e promovendo, possivelmente, a ressignificação dos currículos acadêmicos, a partir de uma análise crítica da realidade que está sendo, com as pessoas e não para elas.
} 
risco de privilegiar a militância, o ativismo, em detrimento de uma reflexão crítica e do estudo teórico, importantes elementos potencializadores da prática da extensão popular. Não podemos desprezar que vivemos no contexto de uma educação bancária, também experienciada nas disciplinas curriculares do curso de Engenharia Ambiental, que acabam por incentivar um afastamento de muitas/os das/os estudantes em relação ao ensino e à pesquisa. Disso decorreu o fato de o grupo extensionista se considerar privilegiado quanto à formação profissional, pois para elas/ele, a extensão se dá na práxis, o que permite rica formação.

Articular as atividades de pesquisa, estudo e ensino com as ações inerentes à prática da extensão popular junto à comunidade de trabalho também foi desafiante. Hoje entendemos que o grupo extensionista é capaz de compreender que estes dois pilares de sustentação da universidade são indissociáveis. Essa percepção se consolidou a partir do momento em que passaram a compor a comunidade de trabalho, na medida em que intensificou a participação nas ações de educação ambiental popular, na reflexão de suas ações, ou ainda, no aprofundamento teórico em alguns temas pertinentes aos problemas vivenciados na realidade da comunidade de trabalho. Acreditamos, no entanto, que a experiência de participar da comunidade de trabalho possibilitou às/aos estudantes construir outras percepções para a atividade de ensino e pesquisa, reforçando e qualificando sua formação profissional e pessoal.

Em um primeiro momento, são as trocas de experiências, seja ao organizar atividades durante os encontros reservados do grupo extensionista, até à proposição e construção conjunta à comunidade de trabalho, as/o estudantes puderam compreender qual a intencionalidade das suas ações, para além da educação ambiental popular, ampliando sua capacidade de reflexão e crítica. Podemos afirmar, desse modo, que essa experiência vivida é também fonte de saberes e caminhos para vivenciar a educação popular na universidade. Mesmo que processualmente, foi a partir de cada atividade proposta e construída junto com a comunidade de trabalho que as/o extensionistas foram percebendo que suas práticas eram permeadas por um saber que precisava ser socializado, para ser difundido entre as pessoas da comunidade de trabalho e para além dela. Desta maneira, a convivência na comunidade de trabalho favoreceu aos estudantes enxergar a riqueza de conhecimentos que carregam, suas experiências e a necessidade de também sistematizá-las.

As/Os estudantes foram também aprendendo que refletir em torno das experiências não era somente "colocar no papel" uma descrição do que podiam fazer posteriormente a cada atividade pensada e proposta colaborativamente, mas também cultivar um tempo próprio para entendê-las em maior profundidade, a fim de resgatar seus princípios teórico-filosóficos, elencando os principais obstáculos identificados em suas ações, evidenciando os principais potenciais e descobertas originadas no desenvolvimento de suas ações e re-pensando as perspectivas de futuro das suas ações, problematizando suas contribuições para a comunidade de trabalho.

As/O estudantes extensionistas foram percebendo que sua prática só poderia ser feita com tempo, cuidado e seriedade, o que não constituía uma atividade a mais em meio a tantas outras, curriculares ou não, ligadas ou não ao curso de Engenharia Ambiental, mas era a extensão popular, permeada pela pesquisa, pelo ensino, uma prática que possibilitou a ação, reflexão, estudo e sistematização.

Quanto ao ensino, as/o extensionistas que participam da comunidade de trabalho puderam desenvolver ações a partir das necessidades de aprendizagem que emergiram de seu confronto crítico com a realidade, seus dilemas e suas incertezas. Ao entrar em contato com diferentes experiências, ficou claro que o ensino pode se fazer pela busca em ser mais de cada uma/um, escolhendo caminhos coerentes com este horizonte, à medida que se faz necessário. As formas participativas de construir diálogos revelaram novas perspectivas de ensinar e aprender, indicando que existem possibilidades de vivenciar o ensino distante das tradições da educação bancária. Percebemos que, no conjunto das experiências da extensão popular 
realizada, surgiu um ensino construído a partir da crítica à realidade concreta, ligada aos anseios e aos saberes das pessoas envolvidas, dedicado aos problemas de interesse da comunidade de trabalho, especialmente com relação à situação-limite imposta pela ausência da passarela entre os bairros (e não apenas dessa situação-limite). Na comunidade de trabalho foi possível trabalhar metodologias coerentes com esse horizonte, marcadas pela valorização do diálogo, das trocas de experiências dotadas de intencionalidade transformadora.

$\mathrm{Na}$ medida em que as/o estudantes se dão conta do potencial existente na ação desencadeada pela pesquisa, ensino e pela própria extensão, é possível concluir que a extensão popular não se limitou ao campo da ação junto à comunidade de trabalho. Constituiu-se como um caminho profícuo para a produção de conhecimentos, bem como para a formação das pessoas também como educadoras ambientais. Desse modo, a extensão popular integrou-se dialogicamente com pesquisa e ensino na construção de conhecimentos úteis à transformação das condições de opressão, de dor, de injustiça, de indignação, de limitação de direitos, de negação da vida, de subjugação ao risco de morte, vividas pelas pessoas que constituem a comunidade de trabalho.

A comunidade de trabalho permaneceu ativa, mesmo quando se manifestava um diálogo desesperançoso, não se deixou perder de vista o horizonte da produção de conhecimentos emancipadores, valorizando e reconhecendo o saber de experiência feito, no sentido colocado por Larrosa-Bondía (2002). Se não tivesse existido um confronto crítico com a realidade, pela imersão comprometida com as pessoas, o conhecimento que nós chamamos de conversitário (FLEURI, 2005) não poderia ter sido construído. Sem uma rigorosa investigação sobre os principais impasses, problemas e até mesmo contradições que permeavam a comunidade de trabalho, a produção desse conhecimento também estaria comprometida.

Entendemos, assim, que o fazer da extensão popular, enquanto prática social, deve integrar extensão, pesquisa e ensino de modo indissociável, a fim de evidenciar que esse tríplice é fundamental para se implementar experiências capazes de fomentar a criticidade e a participação democrática, na tentativa do exercício do poder obediencial, na perspectiva de Dussel (2007). Pela extensão, pode-se favorecer o encontro com a realidade concreta e com as pessoas; pela pesquisa, confrontando-se com o mundo criticamente, questionando-o e buscando conhecê-lo mais aprofundadamente; e pelo ensino, encontrando na extensão e nos caminhos da pesquisa, temas e problemas que podem ser individuais ou coletivamente desenvolvidos, como aconteceu na e com a comunidade de trabalho.

Avançar na produção de conhecimentos científicos emancipadores, ou seja, de um conhecimento conversitário, foi e é um desafio possível de ser enfrentado, uma vez que o posicionamento crítico comprometido com a realidade deve permear e, por isso, potencializar a realização de ações que possibilitem a transformação social. Desse modo, a extensão que se afirma popular se funda em uma relação dialética entre o campo de atuação ético e prático, alimentando ideais, sonhos e esperanças que permitam às pessoas agirem de modo a alcançar uma outra forma de viver coletivamente. Por isso, quando fazemos extensão popular, nutrimos uma perspectiva teórica e epistemológica para a extensão universitária que seja capaz de sugerir caminhos possíveis para outras realizações entre a universidade e a sociedade, e entre a sociedade e a universidade, ou seja, em ambos os sentidos. Esse movimento só ganha significado a partir da solidariedade, da busca pelo enfrentamento da desumanização em curso, pela fraternidade praticada e recheada de amorosidade, alteridade e de valorização da vida. Fazer extensão popular é fazer educação popular, é fazer educação ambiental popular, uma vez que primam, todas elas, por uma racionalidade ambiental emancipadora, com a qual nós podemos ousar acreditar na utopia de um movimento em busca do ser mais. 


\section{REFERÊNCIAS}

BARDIN, L. Análise de conteúdo. Lisboa: Edições 70, 2006.

BOGDAN, R.; BIKLEN, S. Notas de Campo. In: BOGDAN, R.; BIKLEN, S. Investigação qualitativa em educação: uma introdução à teoria e aos métodos. Porto Alegre: Porto Editora, 1994. p.150-175.

BRANDÃO, C. R. Comunidades aprendentes. In: FERRARO JUNIOR, L. A. Encontros e caminhos: formação de educadoras(es) ambientais e coletivos educadores. Brasília: MMA. Diretoria de Educação Ambiental, 2005. p. 83-92.

CRUZ, P. J. S. C. Extensão popular: situando a extensão universitária orientada pela educação popular. In: CRUZ, P. J. S. C.; CARNEIRO, D. G. B.; TÓFOLI, A. M. M. A.; RODRIGUES, A. P. E.; ALENCAR, I. C. (org.). Extensão popular: caminhos em construção. João Pessoa-PB: Editora CCTA, 2017. p. 19-29.

DUSSEL, E. D. 20 teses de política. Buenos Aires: Consejo Latinoamericano de Ciencias Sociales - CLACSO; São Paulo: Expressão Popular, 2007.

DUSSEL, E. D. Para uma ética da libertação latino-americana. 5. ed. São Paulo: Loyola, 1977.

FREIRE, P. Pedagogia da esperança: um reencontro com a pedagogia do oprimido. Rio de Janeiro: Paz e Terra, 2008.

FREIRE, P. Pedagogia do oprimido. São Paulo: Editora UNESP, 2005.

FLEURI, R. M. Conversidade: conhecimento construído na relação entre educação popular e universidade. Educação Brasileira, v. 27, n. 54, p. 11-67, 2005.

JARES, X. R. Pedagogia da convivência. São Paulo: Palas Athena, 2008.

LARROSA-BONDÍA, J. Notas sobre a experiência e o saber da experiência. Revista Brasileira de Educação, n.19, p. 20-28, jan.-abr. 2002.

LOUREIRO, C. F. B. Sustentabilidade e educação ambiental: controvérsias e caminhos do caso brasileiro. Sinais Sociais, v. 9, n. 26, p. 13-38, set.-dez. 2014.

MARCONI, M. A.; LAKATOS, E. M. Técnicas de pesquisa: planejamento e execução de pesquisas, amostragens e técnicas de pesquisas, elaboração, análise e interpretação de dados. 5. ed. São Paulo: Atlas, 2002.

OLIVEIRA, M. W.; SILVA, P. B. G.; GONÇALVES JUNIOR, L.; GARCIA-MONTRONE, A. V.; JOLY, I. Z. Processos Educativos em práticas sociais: reflexões teóricas e metodológicas sobre pesquisa educacional em espaços sociais. In: REUNIÃO ANUAL DA ANPED, 32., 2009, Caxambu. Anais [...]. Caxambu, 2009. p. 1-17.

SAUVÉ, L. Uma cartografia das correntes em educação ambiental. In: SATO, M., CARVALHO, I. (org.). Educação ambiental: pesquisa e desafios. Porto Alegre: Artmed, 2005. p. 17-44.

SILVA, P. B. G. Educação e identidade dos negros trabalhadores rurais do limoeiro. 1987. 293 p. Tese (Doutorado em Educação) - Faculdade de Educação, Universidade Federal do Rio Grande do Sul, Porto Alegre, 1987.

SILVA, P. B. G.; ARAUJO-OLIVERA, S. S. Cidadania, ética e diversidade: desafios para a formação em pesquisa. In: ENCUENTRO - CORREDOR DE LAS IDEAS DEL CONO SUR "SOCIEDAD CIVIL, DEMOCRACIA E INTEGRACIÓN”, 6., 2004, Montevidéo. Anais [...]. Montevidéo, 2004.

SOUZA, T. Z. A extensão popular em educação ambiental e seus processos educativos. 2017. 305 f. Tese (Doutorado em Educação) - Centro de Educação e Ciências Humanas, Universidade Federal de São Carlos, São Carlos, 2017.

TEIXEIRA, I. M. C.; RIBEIRO JUNIOR, D.; SOUZA, E. S.; OLIVEIRA, M. W.; COSTA, R. S.; SOUZA, R. P.; ALMEIDA, S.; BOGADO, A.; SOUSA, F. R.; FIDELIX, A. P.; SOUZA, T. Z. Cosmovisão. Acompanha 
Tiago Zanquêta de Souza

seção de debates sobre Convivência. Texto de Estudos. São Carlos: Grupo de Pesquisa Práticas Sociais e Processos Educativos, Pós-Graduação em Educação da UFSCar - PPGE/UFSCar, 2015.

VALLA, V. V. A crise de interpretação é nossa: procurando compreender a fala das classes subalternas. Educação \& Realidade, v. 21, n. 2, p. 177-190, jul.-dez. 1996.

VERGARA, S, C. Métodos de coleta de dados no campo. São Paulo: Atlas, 2009.

Recebido em: 02 nov. 2021.

Aprovado em: $21 \mathrm{dez} .2021$. 